\title{
High temperature oxidation studies of binary and ternary iron based alloys at $700^{\circ} \mathrm{C}$
}

\author{
H. Rojacz, F. Birkelbach \& M. Varga \\ $A C^{2}$ T research $\mathrm{GmbH}$, Austria
}

\begin{abstract}
The high temperature oxidation of iron-based alloys is a crucial factor in limiting the lifetime of core components operating under extreme thermal conditions. To understand their oxidation mechanisms on a fundamental level, kinetic studies of oxidation were performed within this study. For this, a newly developed high temperature corrosion test (HT-CT) was utilised to oxidise different materials at temperatures up to $700^{\circ} \mathrm{C}$. Several binary and ternary iron-based alloys were selected for investigating the influence of alloying elements: $\mathrm{Fe}-\mathrm{Cr}, \mathrm{Fe}-\mathrm{Ni}$, $\mathrm{Fe}-\mathrm{Al}$, Fe-Cr-Ni. Fundamental investigations of the scale formation including detailed scanning electron microscopic surface and cross sectional analyses were performed on the specimens. The chemical compositions of the formed scales were revealed by using X-ray diffraction analyses. Regression analysis with regard to the oxidational time constant and the square law of oxidation was performed. Statistical evaluations were performed to quantitatively evaluate the different influences on the oxidation behaviour of iron based alloys. The focus of this study is the disclosure of different oxidation mechanisms on the tested model alloys. The influence of individual alloying elements and their interdependence on the oxidation behaviour is presented. The results indicate a high relevance of the alloying elements in iron based alloys on the oxidational stability and can be ranked as $\mathrm{Ni}<<\mathrm{Cr}<\mathrm{Al}$. This ranking can be justified according to diffusion coefficients and the standard formation enthalpy of the oxides and their influence on the formation of oxide layers, which can be statistically compared to the oxidational stability of different model alloys presented within this study.
\end{abstract}

Keywords: high temperature oxidation, oxidation kinetics, iron based alloys. 


\section{Introduction}

Different industrial applications such as furnaces require oxidation resistance at high temperatures [1]. Materials resisting oxidation and the influence of different alloying concepts within those are of great scientific and industrial interest to lower lifetime-costs of core components.

High temperature oxidation (HTO) and the concomitant reaction of metals with oxygen is a diffusion controlled process compensating the concentrations of oxygen and the metal bulk under the substitution of electrons [2]. The oxidant (oxygen) is transported to the metals surface via mass transfer in the gas phase, and then the atom is incorporated within the oxide scale and can further diffuse through the oxide scale onto the boundary zone between metal and oxide scale which can further enhance the oxidation [3].

The mass change due to corrosion is mostly positive due to the absorption of oxygen atoms (logarithmic, linear and parabolic mass gain are known), but different mechanisms can also lead to mass decrease (catastrophic oxidation or break-away oxidation).

Iron based alloys are often used in industrial applications due to economical reasons $[4,5]$. For the prevention of critical oxidation of these alloys, a fundamental understanding on oxidation kinetics and mechanisms is essential. Different alloying concepts can provide sufficient oxidation resistance to heat resistant iron alloys up to $800^{\circ} \mathrm{C}$, such as $\mathrm{Cr}, \mathrm{Ni}, \mathrm{Si}$, Ti and $\mathrm{Mo}[6,7]$. Consequently different oxides can be formed on iron based alloys, which were reported in many studies $[1-3,6,7]$, but the influence of different alloying elements on the oxidation resistance is still not completely understood.

Therefore four different iron based model alloys were investigated at a constant alloying content of $20 \%$. Fe-Cr, Fe-Ni and Fe-Al binary alloys and a Fe$\mathrm{Cr}-\mathrm{Ni}$ ternary alloy were examined regarding their oxidation resistance in a high temperature-corrosion test (HT-CT) [8]. In addition to common microscopic methods X-ray diffraction (XRD) is reported [9] to deliver useful information on oxide formation. The main goals of this study are the understanding of different oxidation mechanisms occurring for different alloying concepts. Statistical evaluations on the kinetics and the different formed oxide scales were performed to reveal graphic representations for the easier understanding of different influences like diffusion coefficient and oxidation time constant.

\section{Experimental}

\subsection{Materials data}

Within this study four different model alloys were examined. Chemical compositions of all materials were set to $20 \mathrm{wt} \%$ of alloying elements. Rods were produced via casting in a vacuum furnace in $\mathrm{SiO}_{2}$ crucibles to achieve the maximum possible purity. For the binary alloys $\mathrm{Fe} 20 \mathrm{Cr}$, $\mathrm{Fe} 20 \mathrm{Ni}$ and $\mathrm{Fe} 20 \mathrm{Al}$ was used for examination. The ternary alloy is represented by Fe10Cr10Ni. 
Typical microstructures of the materials are ferritic $(\mathrm{Fe} 20 \mathrm{Cr})$, ferriticaustenitic $(\mathrm{Fe} 10 \mathrm{Cr} 10 \mathrm{Ni})$, austenitic $(\mathrm{Fe} 20 \mathrm{Ni})$ and a solid solution crystal (Fe20Al), which were analysed via alloy phase diagrams [10].

\subsection{High temperature oxidation tests}

A novel high temperature corrosion test (HT-CT) was developed for corrosion and oxidation studies. The test rig enables a mixture of gases in various concentrations and is given schematically in Figure 1.

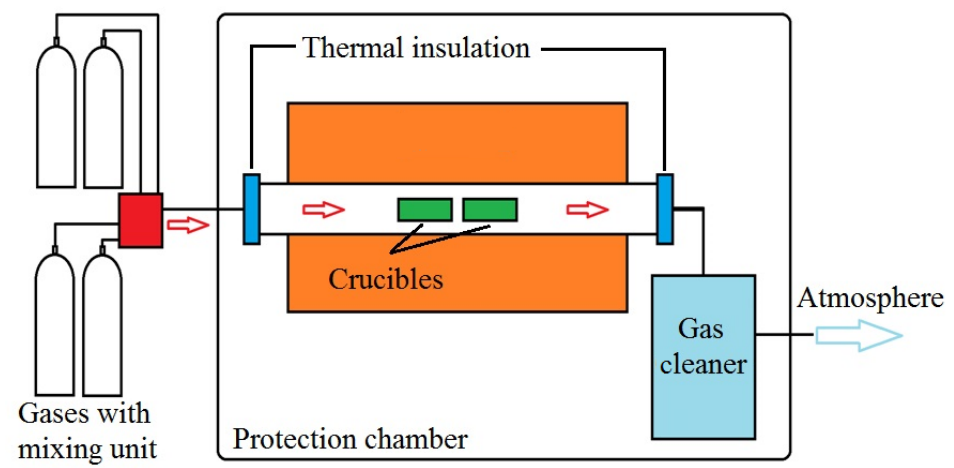

Figure 1: High temperature corrosion test setup.

A tube furnace was reworked with gas feeding and mixture units; gases are controlled by mass flow valves and are fed via a mixing unit into the tube furnace. Alloy samples were cut to $\sim \varnothing 10 \times 7 \mathrm{~mm}$ and grinded. All specimens were weighed and measured with a micrometer calliper for calculating the samples surface area and further the oxidation rate (OR) in $\left[\mathrm{mg} / \mathrm{mm}^{2}\right]$. Four samples of each material were tested. Specimens were inserted in the furnace using $\mathrm{Al}_{2} \mathrm{O}_{3}$ crucibles, the furnace was closed and purged with nitrogen. When reaching $700^{\circ} \mathrm{C}$ the valves inlet synthetic air with $\left(80 \% \mathrm{~N}_{2}\right.$ and $\left.20 \% \mathrm{O}_{2}\right)$, oxidizing the samples. Every $24 \mathrm{~h}$ (up to $192 \mathrm{~h}$ ) samples were cooled down to room temperature in nitrogen atmosphere and were weighed.

\subsection{Analytical techniques and statistical analyses}

Qualitative chemical analyses of the formed oxidation scales were performed using scanning electron microscopy (SEM - Zeiss ${ }^{\circledR}$ Supra EV 50) supported by energy dispersive X-ray diffraction (EDX - EDAX $\left.{ }^{\circledR}\right)$. Stoichiometric phase analysis was performed via X-ray diffraction (XRD - Bruker-AXS D8-GADDS) measurements revealing the synthesised phases present at the different oxide scales.

Quantitative analyses regarding the influences of different parameters influencing the scale formation were performed. Kinetic diagrams of the 
oxidation of all materials were constructed and fitted according the parabolic law of oxidation [1-3] given in formula (1).

$$
\left(\frac{\Delta m}{A}\right)^{2}=k_{p} \cdot t\left[m g \cdot m m^{-2}\right]
$$

where $r \Delta m$ represents the mass gain in $[\mathrm{mg}], A$ the exposed surface area $\left[\mathrm{mm}^{2}\right]$, $\mathrm{k}_{\mathrm{p}}$ the oxidation time constant $\left[\mathrm{mg}^{2} \cdot \mathrm{mm}^{-4} \cdot \mathrm{h}^{-1}\right]$, and $t$ the exposure time in $[\mathrm{h}]$. Statistical kinetic fits were performed using MatLab ${ }^{\circledR}$ software.

The oxidation time constant can be determined via the fit of the data set. Values for $k_{p}$ and the layer thickness can be correlated statistically to diffusion coefficients $D^{0}$ of the alloying elements present and the standard formation enthalpies $\Delta H^{0}[\mathrm{~kJ} / \mathrm{mol}]$ of the formed chemical compounds. Scatter plots, constructed with $R^{\circledR}$, a free software programming language for statistical computing and graphics [11], of the data in correlation with the parameters are presented, revealing their influence. These plots describe the confidence of linear correlations via scatter and intervals.

\section{Results and discussion}

\subsection{Oxidation kinetics of different alloys at $700^{\circ} \mathrm{C}$}

The calculated oxidation rate data and the parabolic fitted curves are plotted in the kinetic diagram presented in Figure 2. The parabolic fit starts at the first measured value for the most proper fit of the oxidation time constant according to the parabolic law of oxidation, before, just a linear approximation is given. Figure 2(a) shows the kinetics of all materials investigated, a better scaling to the more stable alloys is given in Figure 2(b).

A clear influence of the alloyed elements on the oxidation kinetics is visible. Oxidation rates and the calculated oxidation time constants indicate a strong influence of the alloying concept. Alumina forming alloys are highly resistant

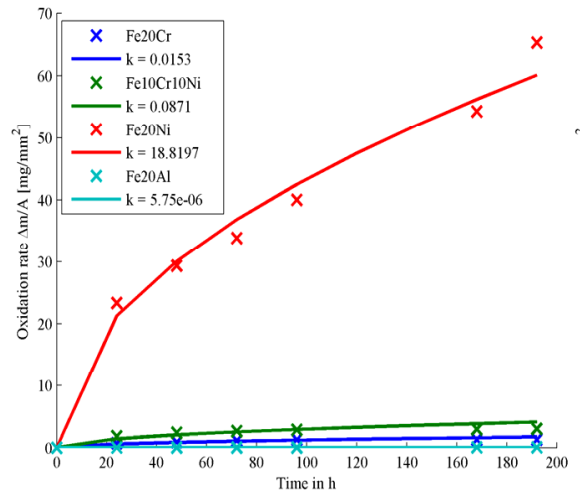

(a)

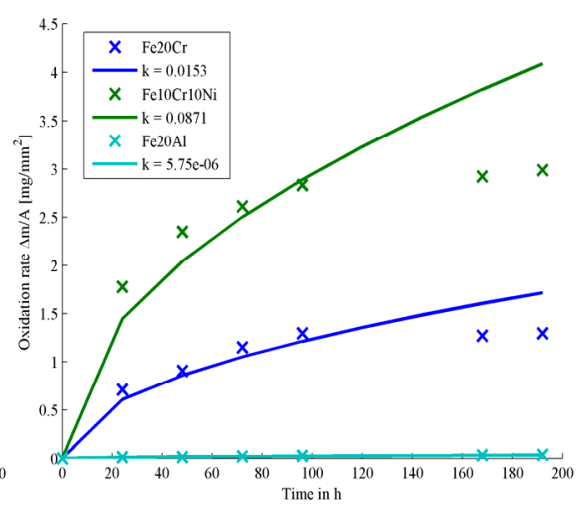

(b)

Figure 2: Oxidation kinetic plots of all materials investigated. 
against oxidation and tend to form oxides very quick, due to the low oxidation time constant $[1,12]$.

Similar fast oxidation provides the chromia forming Fe20Cr. The OR is 30 and the $k_{p}$ is about 2500 times higher, than at the alumina forming material, but nevertheless $\mathrm{Cr}$-oxide can provide dense layer formation entailing high oxidation resistance [13].

The presence of $\mathrm{Ni}$ in Fe-based alloys lowers the oxidation stability of materials, also the satisfying effects of $\mathrm{Cr}$ are lowered dramatically (Fe20Cr:Fe10Cr10Ni = 1:3). Hence Fe20Ni is not suitable in oxidative environment, while chromia and alumina forming alloys are much more satisfying, cf. $[12,13]$.

\subsection{Oxide scale formation at different alloys at $700^{\circ} \mathrm{C}$}

Cross sectional, metallographic analyses of the oxidation scales present at all materials investigated are given Figure 3. Image processing was used to show the different oxide scales formed at different materials.

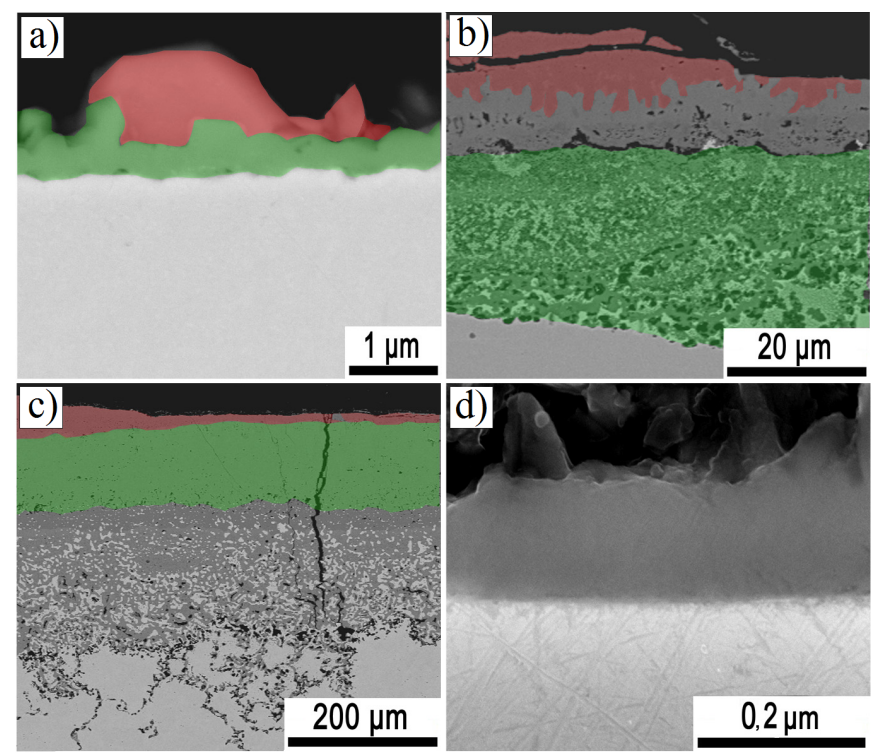

Figure 3: Metallographic cross sectional analyses of the scale formation using SEM: (a) Fe20Cr; (b) Fe10Cr10Ni; (c) Fe20Ni; (d) Fe20Al.

\subsubsection{Fe20Cr}

Figure 3(a) shows a dense oxide scale with a thickness of about $1.5 \mu \mathrm{m}$, consisting of two different layers. The inner layer (green) is a mostly Cr-oxide based scale, consisting of $\mathrm{Cr}_{2} \mathrm{O}_{3}$ and $\mathrm{CrO}_{2}$. The outer layer (red) is iron oxide based and consists of $25 \% \mathrm{Fe}_{3} \mathrm{O}_{4}$ and $75 \% \mathrm{Fe}_{2} \mathrm{O}_{3}$. This can be put down to the 
diffusion coefficients of $\mathrm{Cr}$ and $\mathrm{Fe}$ in iron based materials. $\mathrm{Cr}$ has a lower diffusion coefficient in Fe than Fe itself $[14,15]$. Therefore a dense chromia based layer is formed as an excellent oxidation protection, cf. [13].

\subsubsection{Fe10Cr10Ni}

Figure 3(b) shows a 15 to 20 times thicker scale than the pure $\mathrm{Cr}$ sample. A three-layered structure with visible cracks and concentration gradients within the scale is formed.

At the outside (red) iron oxides $\left(\mathrm{Fe}_{3} \mathrm{O}_{4}\right.$ and $\left.\mathrm{Fe}_{2} \mathrm{O}_{3}\right)$ are formed. Inner regions (grey) mostly consist of Fe-Ni-spinels with very low amounts of $\mathrm{Cr}$. In the diffusion zone (red), which is not yet fully oxidised, Cr-oxides with small amounts of Fe can be detected. For more dense layers, higher amounts of $\mathrm{Cr}$ and $\mathrm{Ni}$ are necessary $[6,7]$. The effects of scale formation can be led back to diffusion - $\mathrm{Cr}$ with its relatively high diffusion coefficient is present at the surface and oxidises, $\mathrm{Ni}$ and iron diffuse to be slower, cf. $[13,15]$.

\subsubsection{Fe20Ni}

Fe20Ni shows a poor scale formation. Also three layers can be detected. At the outside two different oxide scales are formed, at the inner scale a diffusion zone with fragmentary oxidation is visible. XRD and EDX measurements point out mostly $\mathrm{Fe}_{2} \mathrm{O}_{3}$ at the green and the red zones within Figure 3(c).

The outer scale (red) has also small amounts of $\mathrm{Fe}_{0.91} \mathrm{O}$ in it; the inner scale (green) reveals also $\mathrm{Fe}_{2} \mathrm{NiO}_{4}$ in small amounts. The diffusion zone shows a mixture of base material and different oxides.

\subsubsection{Fe20Al}

Fe20Al reveals lowest oxide layer thickness within the test matrix from $\sim 0.8 \mu \mathrm{m}$. A dense alumina layer is visible. XRD-analyses point out $\mathrm{Al}_{2} \mathrm{O}_{3}$-dominated scale formation with small amounts of Fe [cf. 16], which is responsible for a slightly changed lattice parameter [9]. The performed EDX analysis reveals the chemical composition $\mathrm{Al}_{1.95} \mathrm{Fe}_{0.05} \mathrm{O}_{3}$. Due to the high diffusion velocity of $\mathrm{Al}$ in $\mathrm{Fe}$ [18] many Al-atoms are present at the surface and form alumina with small amounts of iron, due to its presence at the surface. The higher negative standard formation enthalpy of alumina compared to iron oxides leads to faster alumina growth, which is also more stable, cf. [19, 20].

\subsection{Quantification of different influences on the oxidation resistance}

Within this section scatter plots are presented revealing the influence of physicochemical properties specific to alloys on the layer thickness and oxidation time constant $\mathrm{k}_{\mathrm{p}}$. The influence of both, standard formation enthalpy $\Delta H^{0}$ and diffusion coefficients $D^{0}$ are shown in Figures 4 and 5 . The red line indicates the root mean square, the green line the linear approximation and the red dotted lines restrict the interval of confidence.

The standard formation enthalpy plots (Figure 4) reveal high dependency of both parameters to $\Delta H^{0}$. A linear fit of the parameters layer thickness and oxidation time constant is applicable, but more accurate correlations should be 
found, by higher amounts of data generated. The influence of $\Delta H^{0}$ on the layer thickness can be clearly pointed out.

The high scatter of the chemical composition of the formed scales and the comparatively low scatter (about $10 \%$ of the values) of the layer thickness make the y-logarithmic linear fit plausible, but the broad confidence interval could be lowered by more or more precise data of the standard formation enthalpy of different compounds, which future tests may reveal.
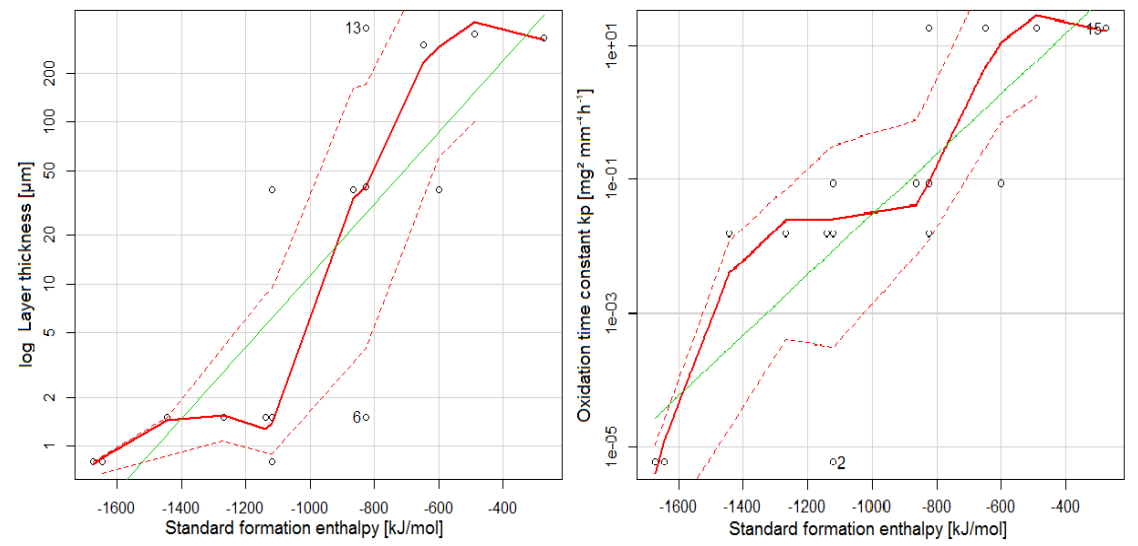

Figure 4: Scatter plots: influence of standard formation enthalpy on layer thickness and the oxidation time constant.

The same is valid for oxidation time constants and their relation to $D^{0}$. A broad scatter was found, but the linear correlation tends to be a valid coherence (as seen in Figure 5).
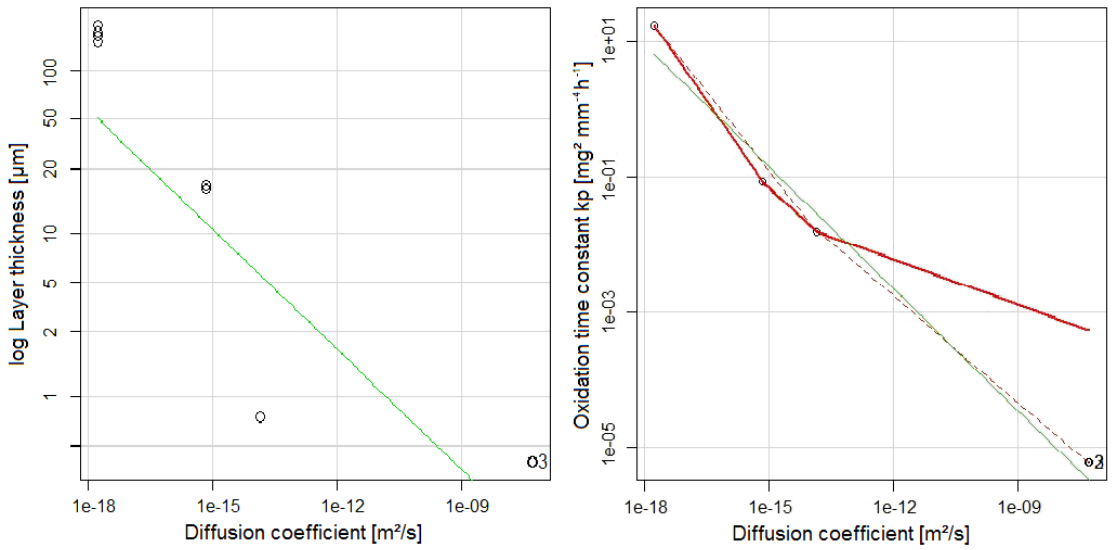

Figure 5: Scatter plots: influence of diffusion coefficients on layer thickness and the oxidation time constant. 
The diffusion coefficient plots reveal high dependency of both parameters on the diffusion coefficient. A linear fit of the parameters is applicable in both cases. Nevertheless, more proper correlations should be found for the layer thickness and the diffusion coefficient by higher amounts of data generated, due to the fact that the linear regression points out high misfits at higher diffusion coefficients. But this also can be originated to the squared influence of the deviation of the red line (root mean square) to the linear fit.

As a consequence of these statistical analyses one must concern, that the formed oxide scales and their physico-chemical parameters cannot be neglected for the formation and the stability of oxidation products and have a crucial influence on oxide formation.

\subsection{Influence of diffusion coefficients and standard formation enthalpy on the oxidation of iron based alloys}

Due to the fact that corrosion is a diffusion-controlled process, the concentration of atoms throughout the material, the boundary zone and the scales plays a major role in oxide formation. The diffusion coefficient, i.e. the velocity of atoms in crystal lattices, plays, as seen in the previous section, a very important role. The ranking of the diffusion coefficients is given in Table 1 .

Table 1: Diffusion coefficients of different atoms in iron.

\begin{tabular}{|c|c|c|}
\hline Atom in solid & Diffusion coefficient $\left[\mathrm{m}^{2} / \mathrm{s}\right]$ & Reference \\
\hline $\mathrm{Al}$ in $\mathrm{Fe}$ & $0.22 \cdot 10^{-7}$ & {$[21]$} \\
\hline $\mathrm{Cr}$ in $\mathrm{Fe}$ & $\sim 1.4 \cdot 10^{-15}$ & {$[15]$} \\
\hline $\mathrm{Fe}$ in $\alpha-\mathrm{Fe}$ & $1.86 \cdot 10^{-15}-1.03 \cdot 10^{-17}$ & {$[14]$} \\
\hline $\mathrm{Ni}$ in $\mathrm{Fe}$ & $\sim 1.7 \cdot 10^{-18}-4.7 \cdot 10^{-18}$ & {$[16]$} \\
\hline
\end{tabular}

As presented in the table, the diffusion coefficients are similarly ranked as the oxidational stability of the materials investigated. For a whole overview on the ranking of the oxidation stability and typical ranges of $\mathrm{D}^{0}$ and $\Delta H^{0}$ are shown in Table 2 .

Table 2: Ranking of materials oxidation stability compared to their physicochemical properties.

\begin{tabular}{|c|c|c|c|c|}
\hline $\begin{array}{c}\text { Material } \\
\text { ranking }\end{array}$ & $\begin{array}{c}\text { Diffusion } \\
\text { coefficient } \\
{\left[\mathrm{m}^{2} / \mathrm{s}\right]}\end{array}$ & $\begin{array}{c}\text { Standard } \\
\text { formation } \\
\text { enthalpy } \\
{[\mathrm{kJ} / \mathrm{mol}]}\end{array}$ & $\begin{array}{c}\text { Oxidation time } \\
\text { constant } \\
{\left[\mathrm{mg}^{2} / \mathrm{mm}^{4} / \mathrm{h}\right]}\end{array}$ & $\begin{array}{c}\text { Oxidation rate } \\
(192 \mathrm{~h}) \\
{\left[\mathrm{mg} / \mathrm{mm}^{2}\right]}\end{array}$ \\
\hline $\begin{array}{c}(1) \\
\mathrm{Fe} 20 \mathrm{Al}\end{array}$ & $0.22 \cdot 10^{-7}$ & -1200 to 1675 & 0.00000575 & 0.061 \\
\hline $\begin{array}{c}(2) \\
\mathrm{Fe} 20 \mathrm{Cr}\end{array}$ & $\sim 1.4 \cdot 10^{-15}$ & -1200 to -1450 & 0.0153 & 1.29 \\
\hline $\begin{array}{c}(3) \\
\mathrm{Fe} 10 \mathrm{Cr} 10 \mathrm{Ni}\end{array}$ & \begin{tabular}{c}
$\sim 3 \cdot 10^{-18}(\mathrm{Ni})$ \\
\hline $\begin{array}{c}(4) \\
\mathrm{Fe} 10 \mathrm{Ni}\end{array}$
\end{tabular} & -600 to -1200 & 0.0871 & 3.13 \\
\hline
\end{tabular}


Similar behaviour can be pointed out at the standard formation enthalpy values of present oxide scales. The more negative the standard formation enthalpy is, the faster the oxide grows, and the harder it is to decompose $[19,20]$.

The $\Delta H^{0}$ of alumina is the lowest $(-1675 \mathrm{~kJ} / \mathrm{mol})$; a highly catalytic reaction of $\mathrm{Al}$ and $\mathrm{O}$ forms very dense, but thin layers with a high resistance against long time oxidation, cf. [17, 18]. Also chromia and Cr-Fe-spinels reveal high standard formation enthalpies from about -1200 to $-1450 \mathrm{~kJ} / \mathrm{mol}$. The formed oxides reveal high oxidation resistance, cf. $[6,7,13]$ but, as seen in the oxidation kinetics in the present study, the reaction is not as fast as on alumina forming alloys (represented by the influence of $D^{0}$ on $k_{p}$ ).

$\mathrm{Ni}$-oxides are in a range from -400 to $-600 \mathrm{~kJ} / \mathrm{mol}$; the iron oxides which are formed on Fe-Ni-alloys show a higher oxidation resistance $(\sim 1200 \mathrm{~kJ} / \mathrm{mol})$ and which results in a more stable growth at the exposed surface. $\mathrm{Ni}$ also tends to inhibit the protective effect of $\mathrm{Cr}$ in $\mathrm{Fe}$; more porous layers are formed.

\section{Conclusions}

Four different iron-based materials with $20 \mathrm{wt} \%$ alloying materials were investigated in oxidative environment at $700^{\circ} \mathrm{C}$. Based on the results of this study, the following conclusions can be drawn:

- The oxidation behaviour of materials is strongly influenced by the alloying elements and their physico-chemical properties.

- The scale formation and the layer thickness can be correlated to the standard formation enthalpy and the diffusion coefficient of the formed scales and can be ranked as $\mathrm{Ni}<<\mathrm{Fe}<\mathrm{Cr}<\mathrm{Al}$.

- The oxidation time constant is also crucially influenced by the formed scales, the diffusion coefficient and the standard enthalpy. The lower the standard formation enthalpy, the more catalytic the reaction with oxygen is and the more dense and thin are the formed layers.

- Fe-Cr and Fe-Al alloys are recommended for applications with oxidative atmosphere at elevated temperatures up to $700^{\circ} \mathrm{C}$. Due to its lack of oxidation stability $\mathrm{Ni}$ should not be alloyed in iron based materials which have to withstand such environments.

\section{Acknowledgements}

This work was funded by the "Austrian Comet-Program" (governmental funding program for pre-competitive research) via the Austrian Research Promotion Agency (FFG) and the TecNet Capital GmbH (Province of Lower Austria) and has been carried out within the "Austrian Center of Competence for Tribology" $\left(\mathrm{AC}^{2} \mathrm{~T}\right.$ research $\left.\mathrm{GmbH}\right)$. The authors are grateful to Dr. Manel Rodriguez-Ripoll for intense discussions. 


\section{References}

[1] Bürgel, R., Maier, H.J. Niendorf, T., Handbuch HochtemperaturWerkstofftechnik, Vieweg+Teubner Verlag: Wiesbaden, 2011.

[2] ASM International, ASM Handbook Volume 13: Corrosion, ASM International: Materials Park, 1991.

[3] Shreir, L.L., Cottis, R.A., Shreir's Corrosion: Management and Control of Corrosion, Elsevier: Amsterdam, 2010.

[4] Davis, J.R., ASM Specialty Handbook: Heat resistant steels, ASM International: Materials Park, 1997.

[5] Lai, G.Y., High Temperature Corrosion and Materials Applications, ASM International: Materials Park, 2007.

[6] Winkelmann, H., Varga, M., Badisch, E., Danninger, H., Wear Mechanisms at High Temperatures. Part 3: Changes of the Wear Mechanism in the Continuous Impact Abrasion Test with Increasing Testing Temperature. Tribology Letters 37, pp. 419-429, 2010.

[7] Winkelmann, H., Varga, M., Badisch, E., Influence of secondary precipitations in Fe-based MMCs on high temperature wear behaviour. Tribology Letters 43, pp. 229-234, 2011.

[8] Priss, J., Rojacz, H., Klevtsov, I., Dedov, A., Winkelmann, H., Badisch, E., High temperature corrosion of boiler steels in hydrochloric atmosphere under oil shale ashes. Corrosion Science 82, pp. 89-292, 2014.

[9] Guinier, A., X-ray diffraction in crystals, imperfect crystals and amorphous bodies, General Publishing Company: Toronto, 1994.

[10] ASM International, ASM Handbook - Volume 3: Alloy Phase Diagrams, ASM International: Materials Park, 1990.

[11] R Development Core Team, $R$ : A language and environment for statistical computing, R Foundation for Statistical Computing: Vienna, 2008.

[12] Zhang, S., Zhao, D., Aerospace Materials Handbook, CRC Press: Boca Raton, 2013.

[13] Gleeson, B., Harper, M.A., The Long-Term, Cyclic-Oxidation Behavior of Selected Chromia-Forming Alloys, Oxidation of Metals 49, pp. 379-399, 1997.

[14] Brandes, E.A., Brook, G.B., Smithells, C.J., Smithells Metals Reference Book, Butterworth-Heinemann: Oxford, 1998.

[15] Lee, B.C.-G., Iijima, Y., Hiratami, T., Hirano, K., Diffusion of $\mathrm{Cr}$ in $\alpha$ Iron, Materials Transactions 32, pp. 255-261, 1990.

[16] Hirano, K., Cohen, M., Averbach, B.L., Diffusion of nickel into iron, Acta Metallurgica 9, pp. 440-445. 1961

[17] Grabke, H.J., Oxidation of $\mathrm{NiAl}$ and $\mathrm{FeAl}$, Intermetallics 7, pp. 1153$1158,1999$.

[18] Prescott, R., Graham, M.J., The Formation of Aluminum Oxide Scales on High-Temperature Alloys, Oxidation of Metals 38, pp. 233-254, 1992.

[19] Lide, D.R., CRC Handbook of Chemistry and Physics, CRC Press: Boca Raton, 2007. 
[20] Atkins, P., De Paula, J., Elements of Physical Chemistry, Oxford University Press: Oxford, 2013.

[21] Neumann, G., Tuijn, C., Self-diffusion and Impurity Diffusion in Pure Metals: Handbook of Experimental Data, Pergamon: Oxford, 2009. 